J. Neurol. Neurosurg. Psychiat., 1958, 21, 239.

\title{
FURTHER OBSERVATIONS ON SUBARACHNOID HAEMORRHAGE
}

\author{
BY
}

\author{
WYLIE McKISSOCK, KENNETH PAINE, and LAWRENCE WALSH
}

From the Department of Neurosurgery, St. George's Hospital, London

This paper is a direct sequel to that of two of the authors (McKissock and Walsh, 1956) in which evidence was produced to suggest that surgical treatment for ruptured intracranial aneurysm led to a lower mortality rate than the $50 \%$ which had been widely accepted as the death rate under conservative treatment. In that paper was collected a series of 108 cases of ruptured aneurysm treated medically during a period when surgical treatment was virtually not practised and in which the death rate was $50 \%$. This was contrasted with a largely subsequent series of 141 patients subjected to surgical treatment with a mortality rate of $33.3 \%$. That the two series were not strictly comparable must be conceded, for the patients were admitted during two different periods at a time when progressively greater interest was being shown in the conditions of subarachnoid haemorrhage and ruptured aneurysm, the techniques of angiography were improving, and the mode of selection of patients for transfer to a neurosurgical unit was changing.

Unfortunately the literature contains no report of a large unselected series of proven ruptured aneurysms treated by medical means alone so that there is no reliable figure for the death rate under these conditions against which the effect of modern surgical methods of treatment can be assessed. Magladery (1955) attempted to compare the results of medical and surgical treatment but his figures were unacceptable for an assessment of the death rate in cases of aneurysm for only 90 of the 235 cases were subjected to angiography and the series treated surgically was too small ( 37 cases) to be significant.

Of the many series of cases reported by surgeons in recent years none can be accepted as giving a correct picture, either because the material had been selected, the number of cases was too small, or the time of operation after haemorrhage was not given.

Norlén and Olivecrona (1953) were discouraged, for example, by a death rate of eight patients of 15 operated upon from a few hours to 22 days after the haemorrhage and concluded that operation should be delayed until the quiescent period of three to four weeks after the bleed when they demon- strated a death rate of only two patients of 63 operated upon. Such a series of 15 cases was too small upon which to dogmatize and a delay of three to four weeks permitted of too large a proportion of deaths from recurrent haemorrhage.

This present paper deals with 261 additional patients shown by angiography, operation, or necropsy to have suffered rupture of an intracranial aneurysm. The patients were admitted during the period April 1, 1954, to June 30, 1956, in which time 455 patients with subarachnoid haemorrhage were admitted to the Neurosurgical Department (Table I).

TABLE I

DIAGNOSIS IN 455 PATIENTS WITH SUBARACHNOID HAEMOR RHAGE

\begin{tabular}{|c|c|c|}
\hline & $\begin{array}{l}\text { No. of } \\
\text { Patients }\end{array}$ & $\begin{array}{l}\text { No. of } \\
\text { Deaths }\end{array}$ \\
\hline $\begin{array}{l}\text { Intracranial aneurysm } \\
\text { Intracranial angioma } \\
\text { Due to specific disease } \\
\text { Aneurysm and angioma } \\
\text { Cerebral or cerebellar haemorrhage } \\
\text { Unexplained subarachnoid } \\
\text { haemorrhage }\end{array}$ & $\begin{array}{r}261(57 \%) \\
26(6 \%) \\
2 \\
1 \\
47(10 \%) \\
118(26 \%)\end{array}$ & $\begin{array}{rr}120 & (46 \%) \\
7 & (27 \%) \\
0 & \\
0 & \\
33 & (70 \%) \\
12 & \end{array}$ \\
\hline Total $\ldots \quad \ldots \quad \ldots$ & 455 & $172(38 \%)$ \\
\hline
\end{tabular}

\section{Unexplained Subarachnoid Haemorrhage}

The clinical importance of this group lies in the better prognosis which can be given when angiography has proved negative, for, of these 118,83 have been followed for periods of six months to over three years with only 12 deaths, a mortality of $14 \%$. It is important to note that 140 patients had negative angiograms, of whom 34 died, 22 of whom were found to have aneurysms at necropsy.

\section{Intracranial Aneurysms}

Our main purpose in this paper is to record the results of our management of the patients with ruptured intracranial aneurysms. In general we considered this condition an emergency and began investigations as soon as the patient reached our unit. After the usual careful history taking, neurological and general examination, the patient's reaction to compression of one and then the other carotid artery 
in the neck for 10 minutes was tried. If the patient tolerated this procedure without any deterioration in the state of consciousness or the development of new neurological signs, bilateral carotid angiography was carried out forthwith. If the patient did not tolerate carotid compression, then angiography was delayed and during the following days increasing periods of carotid compression were carried out until the patient would tolerate the necessary 10 minutes, when angiography was performed. Operation, if indicated, was carried out shortly after angiography, usually within 24 hours of admission, although in certain circumstances operation was delayed for four or five days and occasionally for as long as two weeks. In the main we were concerned with treating all patients with ruptured aneurysms which were surgically accessible with the knowledge that there would be a high mortality and morbidity in patients operated upon soon after the bleed. We believed, however, that this would be lower than the natural mortality and morbidity. In our opinion early angiography was essential for, in the moribund patient, an intracerebral haematoma might be demonstrated and could be at once evacuated whereas in the others there was no means of knowing when a further, and possibly fatal, haemorrhage might occur.

There were 261 patients with intracerebral aneurysms, their anatomical distribution being shown in Table II. These figures corresponded closely with those of previous reports except for the higher incidence of patients with multiple aneurysms which might well be a reflection of improved angiographic technique and interpretation.

TABLE II

SITE OF RUPTURED ANEURYSMS

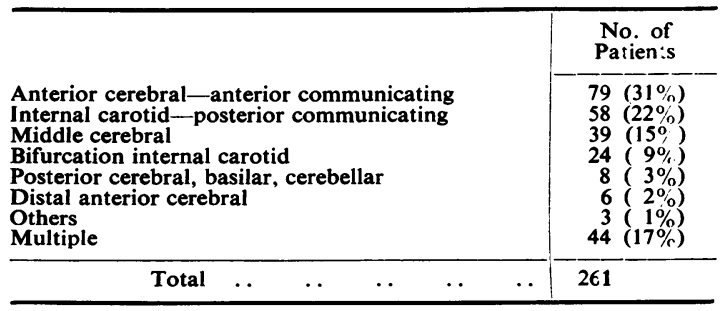

Selection of Patients for Treatment

During the period covered by the admission of the 261 patients of this series the tendency was one of ever-increasing recourse to surgery whenever the aneurysm appeared amenable to such treatment. The reasons for withholding surgery were broadly these: (1) Death before investigation or before surgery could be undertaken; (2) failure to withstand carotid compression; (3) failure to demonstrate the lesion by angiography; (4) unsatisfactory crosscirculation as, for example, in anterior cerebralanterior communicating aneurysms where the operation of choice was an appropriate proximal anterior cerebral clip; (5) a clinical state of akinetic mutism. Surgery would not be withheld because of the poor clinical condition of the patients, many of whom indeed were operated upon when in extremis.

\section{Classification}

The patients were classified in the same manner as in our preceding paper.

Category A.-This category included patients who were in danger of dying in the immediate future from the haemorrhage causing admission to hospital. It also included all those who were in coma or a semiconscious state with severe neurological signs.

Category B.-Patients who had completely, or in part, recovered from the haemorrhage resulting in hospital admission were seen within eight weeks of the last bleed, but were not in danger of dying from that initial haemorrhage. This category in-o cluded patients in good general condition but who might or might not still show some residual signs of haemorrhage. They were still, however, at considerable risk from a further haemorrhage.

Category C.-These patients had recovered completely, or with residual signs in the central nervous system, from the initial bleed but were seen more than eight weeks after the haemorrhage.

In this category most patients were completely well and only a few had residual signs of the brain damage caused by the original haemorrhage. They, of course, were still at some risk from a further haemorrhage, but probably only to the order of about $20 \%$.

\section{Angiography}

Two hundred and fifty-three patients had angiographic investigations and the aneurysm was demonstrated in 231 of these $(91 \%)$. In those patients with more than one aneurysm not all of these in a particular patient were necessarily shown by angiography. In 22 patients the angiogram was negative and the lesion was demonstrated at necropsy or, rarely, at operation. Eight patients died before angiography was performed.

\section{Results of Treatment of Intracranial Aneurysms}

It is most important to stress the fact that all references to mortality indicate death at any time during the stay in hospital or the period of followup. 
TABLE III

RESULTS OF TREATMENT (ALL ANEURYSMS)

\begin{tabular}{|c|c|c|c|c|c|c|}
\hline \multirow[b]{3}{*}{$\begin{array}{l}\text { Untreated } \\
\text { Removal of clot } \\
\text { Exploration only } \\
\text { Carotid ligation } \\
\text { Intracranial opera- } \\
\text { tion }\end{array}$} & \multicolumn{2}{|c|}{ Category A } & \multicolumn{2}{|c|}{ Category B } & \multicolumn{2}{|c|}{ Category C } \\
\hline & No. & Deaths & No. & Deaths & No. & Deaths \\
\hline & $\begin{array}{l}41 \\
13 \\
30 \\
20\end{array}$ & $\begin{array}{l}36 \\
\frac{11}{19} \\
10\end{array}$ & $\begin{array}{r}39 \\
3 \\
67 \\
40\end{array}$ & $\begin{array}{r}\frac{17}{3} \\
12 \\
12\end{array}$ & $\frac{5}{-}$ & $\frac{0}{\underline{0}}$ \\
\hline Totals .. & 104 & 76 & 149 & 44 & 8 & 0 \\
\hline
\end{tabular}

The gross results are shown in Table III. In Category A there were 104 patients, of whom 41 were untreated with 36 deaths $(88 \%)$. The remaining 63 were subjected to some form of operation, of whom 40 died $(63 \%)$.

In 13 of the patients the operation was confined to evacuating an intracerebral clot, sometimes because angiography had not been performed, 11 of whom died $(85 \%)$. In 17 cases intracerebral clots were evacuated in conjunction with some other form of surgery and 13 died $(77 \%)$. The overall mortality in patients requiring removal of a large intracerebral clot was thus about $80 \%$.

Thirty patients had had a carotid ligation, of whom 19 died $(63 \%)$, and 20 had had an intracranial operation and of these 10 died $(50 \%)$.

There were 149 Category B patients and of these $39(26 \%)$ were untreated with 17 deaths $(44 \%)$ and 110 treated surgically with 27 deaths $(25 \%)$. Some of the untreated patients in this group were only shown to have aneurysms at necropsy. Of the surgically treated group, three had had an exploratory craniotomy only and all three had died. In 67 a carotid ligation was performed and 12 died $(18 \%)$. ("Carotid ligation " is taken to mean single or combined ligature of the three carotid vessels in the neck-common, internal, and external.) In 40 patients an intracranial operation was carried out and 12 died $(30 \%)$. In Category B evacuation of an intracerebral clot was performed in conjunction with some other operative procedure in 15 patients of whom four died $(27 \%)$.

In Category $\mathrm{C}$ there were only eight patients, five untreated and three treated by carotid ligation without any mortality.

Considering all cases, 85 had been untreated with 53 deaths $(62 \%)$, and 176 had been treated surgically with 67 deaths (38\%), 45 patients had had an intracerebral clot removed, in 32 cases with some other operative procedure, and 28 died $(62 \%), 100$ had had a carotid ligation in the neck with a mortality of $31(31 \%)$. The mortality of 63 intracranial operations was $25(40 \%)$.

\section{Cause of Death}

Cerebrovascular disease was considered to be the cause of death, though not necessarily the terminal disease, in 110 patients $(92 \%)$. In four untreated cases and one surgically treated case death was due to an unknown cause-unknown because we had no clinical details of the mode of death in a patient who had died some time later having been discharged well from our unit. In five patients who were all surgically treated, the cause of death was unrelated to the cerebral condition or to the operation.

\section{Time of Death}

Death occurred within one month of the first haemorrhage or of operation, in 106 patients $(88 \%)$, 11 died from one to six months after, and only three more than six months after the haemorrhage or operation. The longest survival to death was two years and five months after the subarachnoid haemorrhage which led to admission to our unit.

\section{Influence of Loss of Consciousness at Time of Haemorrhage}

Walton (1956) has shown that the prognosis is worse in patients suffering a coma-producing haemorrhage than in those in whom consciousness is not lost. In our patients a coma-producing haemorrhage occurred in 170, of whom 94 died $(55 \%)$, whilst of 82 with bleeds not producing coma only 25 died $(30 \%)$. Surgical treatment was denied to 60 patients with coma-producing haemorrhages, of whom 46 died $(77 \%)$, whereas of 110 patients treated surgically, 48 died $(44 \%)$. Surgery was withheld from 25 patients who did not lose consciousness as a result of the bleed, of whom seven died $(28 \%)$, whereas 57 were operated upon with 18 deaths $(32 \%)$.

The results in these groups treated with or without operation were not comparable, for non-surgical treatment might well have been due to death before investigation or before surgery could be undertaken.

The roughly comparable death rates in the haemorrhage cases without coma gave no indication of any superiority of surgical treatment.

\section{Age in Relation to Mortality}

Table IV shows the mortality in the series in relation to the age of the patient. It will be seen that

TABLE IV

MORTALITY IN RELATION TO AGE

\begin{tabular}{l|c|c|c|c}
\hline & \multicolumn{2}{|c|}{ Untreated } & \multicolumn{2}{c}{ Surgically Treated } \\
\cline { 2 - 5 } & No. & Mortality (\%) & No. & Mortality (\%) \\
\cline { 2 - 5 } Under 50 years & 31 & 52 & 96 & 32 \\
Over 50 years & 54 & 61 & 80 & 45 \\
\hline
\end{tabular}


for both the untreated series and the surgically treated series patients over 50 years of age did not fare so well as those under 50 years of age. When the figures were broken into decades it was seen that in the untreated group the mortality rose slowly with each decade, whereas the surgical mortality remained fairly constant until the age of 60 years and then rose rapidly in the older patients from approximately $35 \%$ below 60 to over $50 \%$ after 60 years. The proportion of patients operated upon was higher in the younger age groups and this might have been by natural selection-death-or rarely by conscious selection on the part of the physician or surgeon. Up to the age of 50 years $76 \%$ of patients were surgically treated whereas over 50 years only $61 \%$ were operated upon.

\section{Blood Pressure in Relation to Mortality}

Raised blood pressure was found to be an adverse factor in survival of patients after a subarachnoid haemorrhage. For our purposes the maximum normal level of blood pressure was taken to be $160 / 90 \mathrm{~mm}$. Hg. and the pressure recorded on admission was accepted as the patient's usual blood pressure unless there was evidence of previous persistent hypertension when the patient was included as hypertensive.

In nine instances the blood pressure was not recorded. Six of these patients died $(67 \%)$.

One hundred and fifteen patients had a normal blood pressure and 40 of these died $(35 \%), 35$ were untreated with 18 deaths $(51 \%)$, and 80 were treated surgically with 22 deaths $(28 \%)$. Five were treated by removal of intracerebral clot alone and all died, as did the two who had had an intracranial exploration. Forty-four patients had had a carotid ligation in the neck and of these seven died $(16 \%)$, and 29 patients had had an intracranial attack upon the aneurysm with eight deaths $(28 \%)$.

One hundred and thirty-seven patients were hypertensive and 74 of these died $(54 \%)$. Forty-four had been untreated with 31 deaths $(70 \%)$, and 93 treated surgically with 43 deaths $(46 \%)$, eight had been treated by removal of clot only with six deaths $(75 \%)$, and one, who also died, by exploration of the aneurysm. In 56 a carotid ligation in the neck had been performed with 24 deaths $(43 \%)$, and 28 had had an intracranial attack upon the aneurysm with 13 deaths $(46 \%)$.

In all instances, except for removal of an intracerebral clot, the hypertensive patient seemed to fare less well than the normotensive patient.

Time of Operation in Relation to Mortality

The mortality in those patients operated upon
TABLE V

TIME OF OPERATION IN RELATION TO MORTALITY

\begin{tabular}{l|c|c|c}
\hline $\begin{array}{c}\text { Interval between Subarachnoid } \\
\text { Haemorrhage and Operation }\end{array}$ & $\begin{array}{c}\text { No. of } \\
\text { Patients }\end{array}$ & Deaths & $\begin{array}{c}\text { Mortality } \\
\text { Rate (\%) }\end{array}$ \\
\cline { 2 - 3 } Less than one day & 44 & 25 & 57 \\
Two days & 13 & 6 & 46 \\
Three days & 14 & 7 & 50 \\
Four to six days & 26 & 10 & 38 \\
Seven to nine days & 15 & 4 & 27 \\
Ten to thirteen days & 22 & 7 & 32 \\
Two to three weeks & 14 & 3 & 21 \\
Three to six weeks & 18 & 3 & 17 \\
Six to eight weeks & 5 & 0 & 0 \\
Over eight weeks & 3 & 0 & 0 \\
\hline
\end{tabular}

within three days of a haemorrhage was approximately $53 \%$, from the fourth day to the end of the second week the mortality was about $33 \%$, in the next four weeks about $19 \%$, after which there was no death (Table V).

\section{Recurrence of Bleeding after Treatment}

There was evidence of recurrent bleeding after admission to our unit in 16 untreated patients, all of whom died. Thus, of 85 untreated patients, 37 had died from the haemorrhage that had brought them to the Neurosurgical Department. Of the 48 survivors, one-third had had a further haemorrhage which resulted in death. No cases are recorded of patients in whom haemorrhage recurred but not fatally, although some haemorrhages after dischargeog might have escaped our records.

Recurrent bleeding occurred in three treated patients in whom surgery was confined to removal of an intracerebral haematoma but only two of these patients died as a result.

Haemorrhage recurred in 14 patients after carotid ligation and in 13 cases death followed. This seemed a high figure and in many instances was dependent upon the pathologist's view that the haemorrhage in the subarachnoid space or brain was more recent than the haemorrhage before operation. In some instances certainly there was some doubt about this interpretation.

Four patients had had a further haemorrhage after a craniotomy with attack on the aneurysm.

\section{Follow-up in Living Patients}

Of the 141 survivors, 135 had been followed for more than six months, 121 for more than a year, 45 for more than two years, and six for more than three years. The possible follow-up and the percentage follow-up was: one-two years $141(95 \%)$, two-three years $56(80 \%)$, over three years $14(43 \%)$.

\section{Late Follow-up Results}

The quality of the final result in the survivors was also of some interest when comparing the results of treatment. 
Of the 32 untreated survivors, 25 were at full work, though some may have had minimal signs, two were partially disabled, and four were totally disabled and dependent. There was no follow-up in one patient.

Of the 109 survivors after surgical treatment, 76 were at full work, although some may have had minimal signs $-69 \%$ compared with $75 \%$ of the untreated survivors. Sixteen patients were partially disabled and 12 totally disabled. There was no follow-up in five patients.

Of 69 patients surviving carotid ligation, 48 were in full work $(70 \%)$ as were 26 of 38 who had had intracranial operations on the aneurysms $(68 \%)$.

\section{Results of Treatment According to Site of Aneurysm}

Anterior Cerebral-anterior Communicating Aneurysms.-Table VI shows our results for aneurysms on the proximal part of the anterior cerebral artery or on the anterior communicating artery, the commonest site in our experience.

TABLE VI

ANTERIOR CEREBRAL-ANTERIOR COMMUNICATING ANEURYSMS

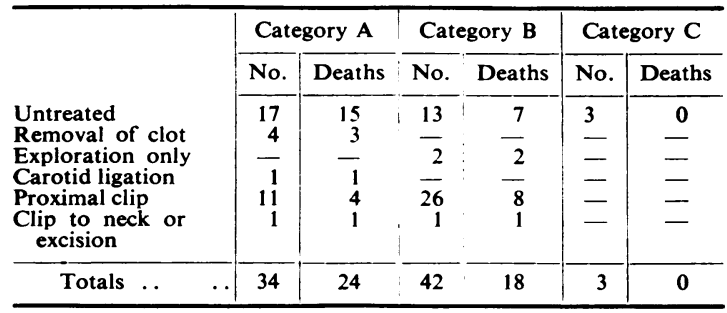

Untreated Patients. - The 17 untreated Category A patients behaved as follows: Five died before investigation, two following a negative angiogram, five had severe neurological disability, two were deteriorating, one died before a planned operation, one was considered too old for surgery, and the final patient did not tolerate carotid compression.

Of the 13 untreated Category B patients, two died from a further haemorrhage before a planned operation, six had an anomaly of the circle of Willis which it was believed would make a proximal clip a hazardous procedure, one did not tolerate carotid compression, one was thought to be too old for operation, and one was seen five weeks after the haemorrhage when she was well. One patient also suffered from haematuria for which reason he was transferred for investigation of the renal tract, and the final patient was rejected for surgery because there was some doubt about the presence of an aneurysm although a recent review of the angiograms confirmed that one was present.

The three Category $\mathrm{C}$ patients were untreated only because they had remained well following haemorrhage over eight weeks before admission to our unit.

Surgically Treated Patients.-Two Category B patients had died following a craniotomy at which it was found inadvisable to clip the anterior cerebral artery.

One Category A patient and two Category B patients had died from recurrent subarachnoid haemorrhage after operation to affix a proximal clip, although in one necropsy showed that the tantalum clip had not been completely closed over the artery. Four Category B but no Category A patients had had an intracerebral clot removed at the craniotomy and all had survived.

Late Results of Treatment.-Of the 11 untreated survivors, eight had returned to full work and two were totally disabled. There was no follow-up in the remaining case.

The one patient who had survived removal of an intracerebral clot remained totally disabled.

Sixteen survivors of a " proximal clip " operation were at full work, four were partially disabled, and five totally disabled.

Blood Pressure and Time of Operation Related to Survival.-The mortality of untreated normotensive patients was $61 \%$ and of hypertensives $74 \%$. Of the surgical group the mortality of the normotensives was $24 \%$ and of the hypertensives $59 \%$.

Twelve patients were operated upon within three days of haemorrhage with a mortality of $50 \%$, nine between four and seven days with a mortality of $44 \%$, eight in the second week of whom five died $(62 \%)$, and 13 after two weeks with only two deaths $(15 \%)$.

Disability Produced by Operation.-After an anterior cerebral clip had been affixed, four patients developed increased mental changes and three increased hemiplegia so that at the follow-up five patients may have had a disability which had been produced by the operation.

Internal Carotid-posterior Communicating Aneurysms.-In our series this was the second commonest site for ruptured aneurysm and Table VII shows our results for this group.

TABLE VII

INTERNAL CAROTID-POSTERIOR COMMUNICATING ANEURYSMS

\begin{tabular}{|c|c|c|c|c|c|c|}
\hline & \multicolumn{2}{|c|}{ Category A } & \multicolumn{2}{|c|}{ Category B } & \multicolumn{2}{|c|}{ Category C } \\
\hline & No. & Deaths & No. & Deaths & No. & Deaths \\
\hline $\begin{array}{l}\text { Untreated } \\
\text { Carotid ligation } \\
\text { Clip to neck and } \\
\text { trapping }\end{array}$ & $\begin{array}{l}5 \\
7 \\
1\end{array}$ & $\begin{array}{l}5 \\
4 \\
1\end{array}$ & $\begin{array}{r}3 \\
36 \\
3\end{array}$ & $\begin{array}{l}1 \\
6 \\
0\end{array}$ & $\begin{array}{l}1 \\
2 \\
-\end{array}$ & $\begin{array}{l}\mathbf{0} \\
\mathbf{0} \\
-\end{array}$ \\
\hline Totals & 13 & 10 & 42 & 7 & 3 & 0 \\
\hline
\end{tabular}


Untreated Patients.-Three Category A patients had not tolerated carotid compression, one died immediately after angiography, and the final one was thought to have had two aneurysms. One Category B patient had had no angiogram as she had not tolerated carotid compression and the other two were seen some weeks after subarachnoid haemorrhage at which time they were well.

Surgical Patients.-Our usual practice when surgery was decided upon was to ligate the common carotid artery in the neck and to evacuate an intracerebral haematoma when necessary. Two Category A patients only had an intracerebral clot evacuated, both of whom died. One Category $A$ and 11 Category B patients developed a hemiplegia postoperatively and six of these died, two had permanent severe disability, and four recovered. Five hemiplegias occurred in the nine patients operated upon within 24 hours of haemorrhage, in three of the 10 operated upon between two and seven days, in one of the nine operated upon in the second week, and in three of the 15 operated upon after two weeks but none in those patients operated upon more than six weeks after haemorrhage.

The overall mortality for carotid ligation was $22 \%$. Recurrence of haemorrhage after carotid ligation occurred with certainty in three hypertensive patients and possibly in two others as well.

Intracranial Operation. - The intracranial operations were clipping of the neck of the aneurysm in two patients and trapping in two others.

Relation of Blood Pressure and Time of Operation to Mortality.-The mortality of the untreated normotensive patients was $25 \%$ and of the hypertensives $100 \%$ (five cases) and for the treated normotensives it was $11 \%$ and for hypertensives $30 \%$.

Five of 15 patients operated upon within three days of haemorrhage died $(33 \%)$, three of the 17 operated upon from four to 14 days after the bleed $(18 \%)$, and four of the 17 operated upon more than two weeks after the haemorrhage $(23 \%)$.

Latest Follow-up Results. - The three untreated survivors were all at full work as were the three who survived an intracranial operation. Thirty-five patients survived a carotid ligation, of whom 28 were at full work, three were partially disabled, and one was totally disabled. There was no follow-up information in the other three patients. In only two instances could the disability at follow-up be attributed to the operation.

Middle Cerebral Aneurysms. - Thirty-nine patients had one middle cerebral aneurysm and Table VIII gives our results for this group.
TABLE VIII

RESULTS OF TREATMENT OF MIDDLE CEREBRAL ANEURYSMS

\begin{tabular}{|c|c|c|c|c|}
\hline \multirow[b]{3}{*}{$\begin{array}{l}\text { Untreated } \\
\text { Removal of clot } \\
\text { Carotid ligation } \\
\text { Exploration only } \\
\text { Craniotomy }\end{array}$} & \multicolumn{2}{|c|}{ Category A } & \multicolumn{2}{|c|}{ Category B } \\
\hline & No. & Deaths & No. & Deaths \\
\hline & $\begin{array}{r}2 \\
2 \\
7 \\
4\end{array}$ & $\begin{array}{l}2 \\
2 \\
5 \\
3\end{array}$ & $\begin{array}{r}\frac{2}{16} \\
1 \\
5\end{array}$ & $\begin{array}{l}1 \\
2 \\
1 \\
2\end{array}$ \\
\hline Totals & 15 & 12 & 24 & 6 \\
\hline
\end{tabular}

Untreated Patients.-Two died before angiography and one after a normal angiogram. The final patient was well when first seen one month after subarachnoid haemorrhage.

Treated Patients.-Angiography had not demonstrated the aneurysm in the two patients whose only treatment was removal of an intracerebral clot.

Carotid Ligation.-During the period under review we were treating middle cerebral aneurysms by common and then internal carotid ligation in the neck and evacuation of an intracerebral haematoma if necessary. Four Category $A$ and two Category $B$ patients had intracerebral clots removed and all six patients died. Six patients developed hemiplegia after carotid ligation, two of whom died, two recovered completely, and two partly. Subarachnoid haemorrhage recurred in three patients after common carotid ligation, and all died, and in one patient after common and internal ligation but he survived.

Craniotomy.-The procedures in these patients were excision in three and trapping in one, all of whom died, obliteration of the aneurysm by tantalum clips in one, and clipping of the neck of the aneurysm in four, one of whom died.

Blood Pressure and Time of Operation Related to Mortality.-In the untreated group one normotensive and one hypertensive patient died but the blood pressure was not recorded in the other two, of whom one survived. Fourteen normotensive patients had a carotid ligation and two died (14\%), whereas of the nine hypertensives five died $(55 \%)$.

For patients operated upon in the first three days the mortality was $58 \%$, in the rest of the first week it was $33 \%$, in the second week it was $36 \%$, and after that $12 \%$.

Late Results of Treatment. - The one untreated survivor had returned to full work. Three survivors of craniotomy were at full work and one was partially disabled. Of the 17 survivors of carotid ligation, 10 were at full work, four were partially disabled, and two were totally disabled. 
Multiple Aneurysms. - Table IX shows our results in this group of patients with more than one aneurysm, but it must be appreciated that in any individual not all the aneurysms present were necessarily demonstrated by angiography.

TABLE IX

RESULTS OF TREATMENT OF MULTIPLE ANEURYSMS

\begin{tabular}{|c|c|c|c|c|c|c|}
\hline & \multicolumn{2}{|c|}{ Category A } & \multicolumn{2}{|c|}{ Category B } & \multicolumn{2}{|c|}{ Category $\mathrm{C}$} \\
\hline & No. & Deaths & No. & Deaths & No. & Deaths \\
\hline $\begin{array}{l}\text { Untreated } \\
\text { Removal of clot } \\
\text { Carotid ligation } \\
\text { Intracranial opera- } \\
\text { tion }\end{array}$ & $\begin{array}{r}11 \\
1 \\
5 \\
1\end{array}$ & $\begin{array}{l}9 \\
0 \\
4 \\
1\end{array}$ & $\frac{14}{7}$ & $\frac{3}{1}$ & $\frac{1}{1}$ & $\frac{0}{0}$ \\
\hline Totals & 18 & 14 & 24 & 5 & 2 & 0 \\
\hline
\end{tabular}

Untreated Patients.-Of the 11 Category A patients, two died before investigation, one before a planned operation, and the other eight were refused surgery solely because of the multiplicity of the lesions. It was for this reason that all Category B and $C$ patients who were untreated were denied surgery.

Treated Patients.-Surgical treatment was instituted in patients with more than one aneurysm for one of four reasons: (1) Only one aneurysm was demonstrated by angiography. (2) Both aneurysms could be treated by the same operation, e.g., carotid ligation, or through the same craniotomy approach. (3) There were conclusive signs indicating which aneurysm had ruptured. (4) An intracerebral clot was present and required evacuation.

In three instances the only aneurysm shown was treated, in three the supposedly ruptured aneurysm was operated upon, 10 were treated by carotid ligation, and in one patient two aneurysms on the same middle cerebral artery were clipped.

In only one patient did necropsy show that two aneurysms had ruptured but this patient had died before angiography.

Carotid Ligation.-Three Category A and one Category B patients had had an intracerebral clot removed in addition to ligation and two of these had died. Two Category A and two Category B patients developed a hemiplegia after ligation. The former two died and the latter pair made an almost complete recovery.

Intracranial Operations.-In three patients the ruptured aneurysm was clipped at its neck and one died, and the fourth patient had the aneurysm trapped but he also died.

Relation of Blood Pressure to Mortality.-Ten untreated patients were normotensive, of whom four died $(40 \%)$, and 15 hypertensive, of whom seven died $(47 \%)$. The mortality of the surgically treated normotensive patients was $31 \%$ and of the hypertensives $48 \%$.

Latest Results of Treatment.-Ten untreated survivors were at full work, two were partially disabled, and two totally disabled. Nine surgical survivors were at full work, one was partially disabled, and one totally disabled.

Terminal Carotid Aneurysms.-Table X shows our results for aneurysm in this situation.

TABLE $X$

RESULTS OF TREATMENT OF TERMINAL CAROTID ANEURYSMS

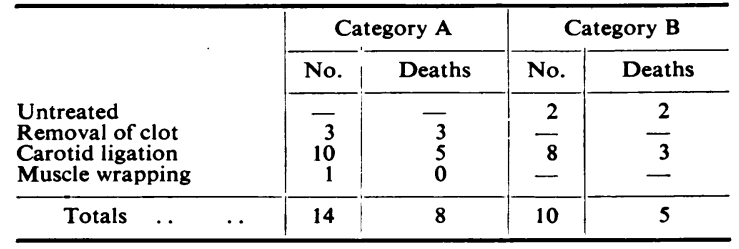

Untreated Patients.-One died before angiography and the other had a normal angiogram.

Treated Patients.-No angiogram was performed on any of the patients whose only treatment was evacuation of an intracerebral clot.

Carotid Ligation.-Four Category A patients and one Category B patient had had an intracerebral clot removed in addition to the ligation and three of the former died. Two Category $A$ and four Category B patients had had the internal carotid artery ligated two or three weeks after common carotid ligation without further mortality. Hemiplegia followed common carotid ligation in four patients, three of whom died but the fourth recovered so as to be able to carry on with her housewifely duties. Four patients had a recurrence of haemorrhage after carotid ligation but in three the necropsy showed an infarcted hemisphere also and this might well have been the cause of death.

Relation of Blood Pressure and Time of Operation to Mortality.-Eight normotensive patients had had a carotid ligation, of whom three died $(37 \%)$, whereas five of 10 hypertensive patients succumbed $(50 \%)$.

Seven of the 14 patients operated upon within a week of haemorrhage died $(50 \%)$ and one of three operated upon in the second week.

Late Results of Treatment.-Of the patients who survived surgical treatment, six were at full work, two were partly disabled, and two totally disabled. There was no follow-up in one patient. 
Distal Anterior Cerebral Aneurysm.-There were six patients with an aneurysm on the anterior cerebral artery distal to the anterior communicating artery. One patient died before investigation and one first seen five weeks after haemorrhage was also denied surgical treatment.

Treated Patients.-One patient had had an evacuation of an intracerebral haematoma before angiography but he died. Three patients had had a direct attack on the aneurysm which all survived.

Late Results. - The untreated survivor remained well as does one of the surgical patients but the other two were disabled, one partially and one totally.

Basilar Aneurysms.--Six patients had basilar aneurysms, three Category $\mathrm{A}$, of whom one survived, and three Category B, all of whom died. One patient died before investigation and two after negative carotid angiography. The aneurysm was diagnosed by vertebral angiography in the other three patients. The only survivor was known to be alive two years later.

Posterior Cerebral Aneurysm.-There was only one such case and this was diagnosed by vertebral angiography in a patient who has remained well during follow up.

Posterior Inferior Cerebellar Artery Aneurysm.Again we had only one example which was found at post-mortem examination, the patient having had a negative carotid angiogram shortly after admission.

Aneurysms at Other Sites.-Two patients had aneurysms on the peripheral branches of the middle cerebral artery; both were Category A patients who were treated by the removal of an intracerebral clot and neither patient survived operation.

One patient with normal carotid angiograms was found at necropsy to have an aneurysm in the wall of the lateral ventricle. Her only treatment had been evacuation of an intracerebral clot carried out under artificial respiration.

Patients not Referred to the Neurosurgical Unit

To get a true picture of the course of patients with subarachnoid haemorrhage we felt that it was essential to obtain information about all those patients admitted to associated hospitals but not referred to our unit. To obtain such information the physicians were asked to cooperate in completing questionnaires about the patients with proven subarachnoid haemorrhage admitted during the relevant period (April 1, 1954, to June 30, 1956) eliminating as far as possible those patients with a primary intracerebral haemorrhage. This was neces- sary for we wished to compare the fate of these patients with those reported by other authors where primary intracerebral haemorrhages were also excluded. In general, the older hypertensive patient who developed a severe hemiplegia as a result of a cerebral catastrophe was excluded unless the necropsy showed the presence of an aneurysm or an angioma. As very few necropsies were performed upon this group of patients the figures are not unduly weighted with those patients with aneurysms who had died and of course, some patients with primary intracerebral haemorrhage who survived without gross neurological defect might also be included. We realized the limitation of this form of review and its inaccuracies, but felt that it might be of some help in assessing the results of surgery in those patients with subarachnoid haemorrhage due to ruptured aneurysm.

Case records of 340 patients were considered suitable for inclusion, of whom 92 had been shown to have an aneurysm either by angiography or at necropsy. Ten had an angioma and 16 had negative angiograms. Twelve patients with aneurysms had been operated upon at other neurosurgical units. Analysis of this group of patients revealed that their average age was slightly higher than that of the patients admitted to the neurosurgical unit (56 years compared with 49 years), and that $59 \%$ were hypertensive compared with $48 \%$ of those admitted to our unit. This difference may have been only a reflection of the poorer prognosis in the older and hypertensive patient.

Of the 340 cases, 198 died $(58 \%)$, 58 dying within 24 hours of the onset of haemorrhage. Five of the 12 patients treated at other neurosurgical units also died $(42 \%)$.

The true picture of the mortality of patients with subarachnoid haemorrhage admitted to general hospitals associated with our unit can only be obtained by combining the two groups of patients, those transferred to a neurosurgical unit and those not so transferred. Thus we have a total of 748 patients (Table XI) of whom 337 died $(45 \%)$, a

\section{TABLE XI}

RESULTS IN ALL CASES OF SUBARACHNOID HAEMORRHAGE

\begin{tabular}{|c|c|c|c|c|c|c|}
\hline \multirow[b]{3}{*}{$\begin{array}{l}\text { Aneurysms } \\
\text { Angiomas } \\
\text { Other causes } \\
\text { Unexplained }\end{array}$} & \multicolumn{2}{|c|}{$\begin{array}{l}\text { Outside } \\
\text { Hospitals }\end{array}$} & \multicolumn{2}{|c|}{$\underset{\text { Unit }}{\text { Neurosurgical }}$} & \multicolumn{2}{|c|}{ Totals } \\
\hline & No. & Deaths & No. & Deaths & No. & Deaths \\
\hline & $\begin{array}{r}92 \\
10 \\
238\end{array}$ & $\begin{array}{r}87 \\
5 \\
106\end{array}$ & $\begin{array}{r}261 \\
26 \\
3 \\
118\end{array}$ & $\begin{array}{r}120 \\
7 \\
0 \\
12\end{array}$ & $\begin{array}{r}353 \\
36 \\
3 \\
356\end{array}$ & $\begin{array}{r}207 \\
12 \\
0 \\
118\end{array}$ \\
\hline Totals & 340 & 198 & 408 & 139 & - & - \\
\hline
\end{tabular}

Totals of all cases: 748 -deaths $337(45 \%)$ 
mortality given by Walton (1956) as the average for conservatively treated series of patients reported in the literature, but usually calculated only from hospital deaths. Walton's figures for the same period of time (first eight weeks) was also $45 \%$ and in our series for the same period was $40 \%$ (296 deaths out of 740 patients).

\section{Discussion}

Our results for treatment of aneurysms both collectively and at the different anatomical sites show a lower mortality for surgically treated patients. Reasons can, however, be found to explain the poorer results of the untreated patients and to show that the operated patients are a somewhat selected group, albeit selected by the natural course of the disease rather than the deliberate selection of the surgeon. One large group of untreated patients is that with anterior communicating aneurysms, 33 patients with a mortality of $67 \%$. We find, however, that some patients died before investigation and some after a negative angiogram so that these patients cannot be compared with any surgical group where demonstration of the aneurysm was an essential preliminary to surgery. In addition some patients died between angiography and the time for a planned operation and these again must be excluded for purposes of comparison. Excluding such patients we are left with only 15 untreated patients of whom six died $(40 \%)$. In contrast 39 patients had an operation with the intention of clipping the anterior cerebral artery, although in two this was not in fact done, of whom 14 died $(38 \%)$, whereas the mortality for all patients undergoing craniotomy was $39 \%$. Our apparent surgical success may thus easily be explained away.

Of the nine untreated patients with internal carotid aneurysms, only three had had a positive angiogram and all three survived. Similarly of the untreated patients with a middle cerebral aneurysm, only one had a positive angiogram. These groups of untreated patients are too small for comparative purposes.

The group of patients with multiple aneurysms naturally includes patients whose only reason for being denied surgery was the presence of multiple aneurysms and the impossibility of determining which one had ruptured. These might form a suitable control group to compare with the treated patients. Twenty-three such patients were untreated with nine deaths $(39 \%)$. After demonstration of the aneurysm by angiography, 17 patients were subjected to operation, of whom seven died $(41 \%)$. Although it is agreed that there will again be differences between the untreated and treated groups as far as blood pressure, age at time of admission or operation are concerned, these differences will be of a more random nature than in the groups of patients with a single aneurysm previously discussed. In our group of patients with more than one aneurysm, therefore, we have shown that the untreated patients fare as well as the treated patients considering only those who have had aneurysms demonstrated by angiography.

Let us compare the results of the untreated and treated patients for the whole group of intracranial aneurysm discarding in the same way as above patients who cannot reasonably be included. We have now a group of 45 untreated patients, of whom 16 died $(36 \%)$. (The patients with basilar and posterior cerebral aneurysms have been excluded.) One hundred and sixty-three patients were operated upon after an aneurysm had been demonstrated and of these 56 died $(34 \%)$. Obviously there is no significant difference between the groups.

Considering Category A patients the mortality of the untreated patients (with the exceptions as before) was $72 \%$ and of the treated patients $64 \%$. The difference is not statistically significant because of the small numbers involved-11 and 63 patients.

Category B patients who were untreated had a mortality of $28 \%$ (excluding patients with no angiogram or normal angiogram) whereas the surgical mortality of Category B patients was $25 \%$. Again there is obviously no statistical difference.

This analysis shows that, for the period of time we have been able to follow these patients, the mortality of untreated patients and treated patients is the same if we make an endeavour to compare only those cases with similar features. In fact, more detailed analysis of the groups shows that the surgical group does contain the more favourable patients, i.e., normotensive, younger age groups, Category B, operation after one week, etc., which but reveals the impossibility of a retrospective statistical analysis.

We next compared the results of treatment in all patients with subarachnoid haemorrhage admitted to our associated hospitals with groups of patients reported in the literature, the vast majority of whom had been treated conservatively. The average for reported series of patients is $45 \%$ (quoted by Walton, 1956), although, unfortunately, the range in the different papers is great. Walton's figures for his own large series is, however, in agreement with the average. We found that for 748 cases with subarachnoid haemorrhage admitted to hospitals with which we are associated, the mortality was $45 \%$ (follow-up time varying from a month to three years) but only $40 \%$ in the first eight weeks although over a quarter of these patients were operated upon. Certainly any surgical success we may have had does not appear to have significantly altered the 
average outlook for the patients with subarachnoid haemorrhage admitted to general hospitals.

Any analysis of our figures which makes some attempt to obtain comparable untreated and treated patients fails to reveal any statistical difference in mortality, and, indeed, statistical evaluation is not usually necessary for it to be apparent that the untreated patients fare as well as the treated ones.

\section{Conclusion}

At the present time there is no conclusive evidence indicating the natural death rate in a large series of unselected cases of ruptured intracranial aneurysm and so there can be no proof of the value of surgical treatment in this condition. Manipulation of the figures for our own large series of patients can readily show that the untreated appear to fare as well as those operated upon. We have thus been forced to the conclusion that the truth of this controversial matter can only be established by a pre-planned campaign.

After consultation with neurologists in no way associated with our unit and with a statistician, we formulated such a scheme and put it into action on January 1, 1958. Briefly, all patients suffering from a ruptured aneurysm, which has been demonstrated by angiography and which, in the opinion of the surgeon, is amenable to surgical treatment, will be admitted to the trial series. Conservative or operative treatment will be allotted by random selection from previously prepared cards.

It will probably be necessary to acquire some 350 patients in the trial series in order to obtain a significant result which we hope to achieve in a period of less than two years. It will then be possible, for the first time, to determine the natural death rate of the condition and the results of surgical treatment 'at our hands.

We wish to thank Mr. Valentine Logue for permission to use records of patients who were under his care and also the many physicians of associated hospitals who so readily made available details of their patients with subarachnoid haemorrhage.

We also thank the Board of Governors of St. George's Hospital for the research grant made to one of us (K.W.E.P.), which has made the collection of this material possible.

\section{REFERENCES}

McKissock, W., and Walsh, L. (1956). Brit. med. J., 2, 559. Magladery, J. W. (1955). J. Neurosurg., 12, 437.

Norlén, G., and Olivecrona, H. (1953). Ibid., 10, 404.
Walton. J. N. (1956). Subarachnoid Haemorrhage. E. \& S. Livingstone, Edinburgh and London. 